\title{
Unani Formulation Improved Quality of Life in Indian Patients of Chronic Hepatitis B
}

\author{
Shabnam Ansari ${ }^{1, *}$, Mohammad Akhtar Siddiqui $^{2}$, Sharad Malhotra ${ }^{3}$, Mohammad Maaz ${ }^{2}$ \\ 'Department of Biotechnology, Faculty of Natural Sciences, Jamia Millia Islamia, New Delhi, INDIA. \\ 2Department of Moalajat, School of Unani Medical Education and Research, Jamia Hamdard, New Delhi, INDIA. \\ ${ }^{3}$ Department of Gastroenterology, Batra Hospital and Research Center, New Delhi, INDIA.
}

\begin{abstract}
Background: Chronic Hepatitis B (CHB) is a serious global healthcare burden with more than 257 million people infected worldwide. Patients of CHB gradually develop derangement in their physical and mental health with the chronicity of the disease. Unani medicine provides a holistic herbal treatment worthiest in the scenario of treatment strategy for chronic viral diseases with deranged quality of life. This study was conducted to evaluate the effect of Unani drugs on deranged quality of life in patients of $\mathrm{CHB}$. Methods: In a pilot clinical trial, 30 patients of chronic Hepatitis B were evaluated for the improvement in their Quality of Life (QoL) after subjected to treatment with decoction of Saussurea lappa and Artemisia absinthium. Enrolled study subjects received treatment for 90 days and were assessed for QoL with a booklet of the instruments [EQ5D (EuroQol 5D-3L), HQLQ ${ }^{\text {TM }}$ (Hepatitis quality of life questionnaire) and physical symptoms] at baseline, $7^{\text {th }}, 45^{\text {th }}$ and $90^{\text {th }}$ day. Results: Significant improvement was observed on EQ5D, HQLQ ${ }^{\text {TM }}$ and physical symptoms. Conclusion: Decoction of Sau-
\end{abstract}

ssurea lappa and Artemisia absinthium improved quality of life in the patients of chronic Hepatitis B. Further studies should be conducted to evaluate their effectiveness in improving quality of life in Hepatitis B induced cirrhosis of liver and hepatocellular carcinoma patients.

Key words: Chronic Hepatitis B, Quality of life, EQ5D, HQLQ, Unani medicine, Saussurea, Artemisia.

Correspondence

Dr. Shabnam Ansari,

Department of Biotechnology, Faculty of Natural Sciences, Jamia Millia Islamia110025, New Delhi, INDIA.

Phone: +91-9818168642

Email: drshabnamansari.md@gmail.com

DOI: 10.5530/jyp.2019.11.73

\section{INTRODUCTION}

Hepatitis B is a major public health problem with an estimated 257 million chronically infected persons, particularly in low- and middleincome countries (LMICs) like India. ${ }^{1}$ Chronic Hepatitis B (CHB) is a chronic necro-inflammatory condition of the liver defined as persistence of hepatitis B surface antigen (HBsAg) for six months or more. An estimated 650,000 people will die annually due to its complications such as cirrhosis of and Hepatocellular Carcinoma (HCC). ${ }^{2}$

CHB patients usually suffered from repeated bouts of liver damage which may clinically present with jaundice, pain in abdomen, nausea, vomiting, fever, diarrhea, loss of appetite, weakness, tiredness, joint pain, work loss etc. Symptomatic CHB results in impaired health related quality of life in patients. It is observed that the patients with more chronicity of disease have more deranged quality of life. Negativity about social life and health has also been observed in chronic patients. ${ }^{3-5}$

Antiviral agents such as entecavir, tenofovir and peg-IFN against HBV are available which have been shown to suppress HBV replication. However, conventional treatment fail to eradicate the virus in most of those treated patients and doesn't provide much relief to the associated symptoms. ${ }^{6}$ Nevertheless, adverse effects of conventional treatments such as fever, neutropenia, thrombocytopenia, gastrointestinal disturbances (nausea, vomiting, diarrhea etc.), potential nephropathy, neuropathy etc. more or less worsen the health status of the patients, leading to more derangement in quality of life. ${ }^{2,5}$

On the other hand, Unani medicine provides a holistic approach in the treatment of chronic Hepatitis B. Unani medicine (Greeco-Arab medicine) is one of the oldest traditional system of medicine and primar- ily based on the theories of homours and temperament of Hippocrates (Buqrat 460-377 BC), the 'father of medicine' also father of Unani medicine'. Later on, Galen (Jalinoos), Rhazes (al Razi), Avicenna (Ibn-e-Sina), Al-Zahrawi and Ibn Nafis are few of the names who have developed this medicine into an elaborate medical treatment. Unani medicine provide various range of treatment approaches for health maintenance and disease recovery starting from prevention, rehabilitation, drugs treatment and even surgery. Mostly (99\%), drugs of herbal origin are utilized for treatment. Various herbal drugs are recorded to be beneficial as liver tonics in Unani medicine. Some of these herbal drugs have not only been substantiated for their potent antiviral, anti-inflammatory and hepatoprotective activities but also evidenced to relieve disease symptoms. ${ }^{78}$ Thus, with this purview following clinical study was carried out which aims to evaluate the efficacy of decoction of root of Saussurea lappa, CB Clarke (qust) and plant of Artemisia absinthium Linn (afsanteen) in the quality of life of the patients of chronic Hepatitis B. Both of these Unani drugs have been used as liver tonic in Unani medicine ${ }^{9}$ and substantiated their antiviral, hepatoprotective, immunomodulatory activities in various studies. ${ }^{10-12}$

\section{MATERIALS AND METHODS}

\section{Ethics statement}

The protocol was approved by the Institutional Ethics Committee affiliated with study center and was implemented in accordance with provisions of the Declaration of Helsinki and ICMR Good Clinical Practice guidelines. All the participants provided their written informed consents to participate in this study. [CTRI No. CTRI/2017/11/010386] 


\section{Study design}

An open, prospective, single arm pilot clinical trial was conducted to study the effects of decoction of root of Saussurea lappa, CB Clarke (qust) and plant of Artemisia absinthium Linn (afsanteen) on quality of life in the patients of chronic Hepatitis B at Majeedia Unani Hospital (MUH), Jamia Hamdard, New Delhi, India during the years 2015-2017.

\section{Participant's eligibility, recruitment and informed consent}

Through a protocol defined screening process, patients of Hepatitis B with clinical history greater than six months were invited through invitation pamphlets. Pamphlets were posted on the various notice boards of the Majeedia Unani hospital, H.A.H Centenary hospital and nearby areas of Jamia Hamdard University New Delhi, India. OPD and IPD patients of Majeedia Unani Hospital (as they come for traditional treatment) were invited specifically by giving them pamphlets individually. Patients were also invited through Facebook by uploading study pamphlet at various hepatitis groups and pages.

Interested patient were described about the study, objectives, screening criteria's, inclusion and exclusion criteria's, study duration, intervention, investigations and probable outcomes verbally as well as providing them with patient information sheet. Interested voluntary Hepatitis B patients between 18-60 years old who had history of positive HBsAg greater than 6 months were screened for inclusion and exclusion criteria's of the study. 70 patients were initially investigated with haemogram, liver function test, viral profiles, kidney function test, blood sugar, urine routine examination and ultrasound abdomen. Among 70 patients who were fulfilling the following inclusion and exclusion criteria's were asked to join the study. Inclusion criteria's were 1) 18-60 years old men and women, 2) HBV DNA $>2000 \mathrm{IU} / \mathrm{mL}$ and 3) ALT (alanine amino transferase) $>2$ times of upper limit of normal. Exclusion criteria's included 1) pregnant women and lactating mothers; 2) mentally retarded person; 3) patients who fail to give informed consent; 4) patients with cirrhosis of liver, portal hypertension/ ascites and obstructive jaundice; 5) patients of diabetes, hypertension, kidney and heart disease and 6) patients of neurological disorder.

Those fulfilling the inclusion and exclusion criteria's mentioned above, were given the patient information sheet attached with Case Record Form (CRF) regarding the nature of the study, the drugs to be used and the study procedure. They were given enough time to go through the study details as mentioned in the patient information sheet.

Patients were given the opportunity to ask any question and if he/she agreed to participate in the study, he/she was asked to sign the informed consent form. The benefits and possible risks of participating in the study were carefully explained, patient confidentiality guaranteed. Patients were made clear that participating in the study was neither a prerequisite for receiving care from Majeedia Unani hospital nor their refusal would affect their treatment and care. Written informed consent was taken from the patients in their known languages in the presence of 2 witnesses and signed by them.

After obtaining written informed consent, attached quality of life questionnaires were filled. Participants had the choice to complete questionnaires face to face at the clinic either by self (self-administered) or by interviewer (interviewer administered). Accordingly Hindi, Urdu and English version were made available to the patients as possible. 34 patients were allocated to intervention and follow up was done on $7^{\text {th }}, 45^{\text {th }}$ and $90^{\text {th }}$ day. Among these 34 patients, 30 patients completed the protocol with full dataset and were analyzed.

\section{Intervention}

Saussurea lappa and Artemisia absinthium were purchased from the local market at Khari Baoli, Old Delhi, India and were authenticated by Prof. (Dr.) M.P Sharma, Department of Botany, Faculty of Science, Jamia Hamdard, New Delhi, India.

Qualified participants received $15 \mathrm{ml}$ of decoction of qust (Saussurea lappa) (containing approx. $1 \mathrm{~g}$ of dried extract) in the morning empty stomach and $15 \mathrm{ml}$ of decoction of afsanteen (Artemisia absinthium) (containing approx. $1 \mathrm{~g}$ of dried extract) in the evening empty stomach daily for 90 days. Follow up was done on $7^{\text {th }}$ day, $45^{\text {th }}$ day (Mid-treatment) and $90^{\text {th }}$ day (After treatment).

\section{Study instruments and end points}

Different questionnaires for assessing the Quality of Life (QoL) in patients of chronic Hepatitis B were utilized..$^{13}$ Assessment was done at baseline, $7^{\text {th }}$ day, mid treatment $\left(45^{\text {th }}\right.$ day) and after treatment $\left(90^{\text {th }}\right.$ day)

Once written informed consent was obtained, enrolled patients were provided a booklet of the instruments (EQ5D, HQLQ and physical symptoms) in available Hindi, English and Urdu version to complete during their visit. Only face to face (self or interviewer administered) manner was performed. The time taken for patients to complete the array of instruments ranged from 30-45 $\mathrm{min}$. These instruments have also been used to measure HRQoL (health related quality of life) in patients with chronic Hepatitis B infection. ${ }^{13-15}$ Permission to utilize these questionnaires was taken from their respected copyright agencies.

\section{1) EuroQol-5D-3L ${ }^{\mathrm{TM}}(\mathrm{EQ} 5 \mathrm{D})$}

EQ5D is a generic instrument for measuring quality of life. The EQ5D3L essentially consists of: - the EQ-5D descriptive system and the EQ visual analogue scale (EQ VAS) ${ }^{16,17}$ EQ5D was assessed at baseline, mid treatment and after treatment.

\section{a) The EQ5DVAS}

Records the patient's self-rated health on visual analogue scale used in the EQ5D as a vertical line on a page with a 0 at one end representing worst possible health and 100 at the other end representing best possible health. The preference score is the measurement of the distance between zero and the mark made by patient, indicating his or her current health state before and after treatment for the efficacy of a particular treatment. ${ }^{16,17}$ Significant increase in VAS ratings at mid and after treatment Vs. baseline were considered as improvement in health status.

\section{b) The EQ-5D-3L descriptive system}

Comprises of the following 5 dimensions: mobility, self-care, usual activities, pain/discomfort and anxiety/depression. Each dimension has 3 levels: no problems, some problems, extreme problems. The patient were asked to indicate his/her health state by ticking (or placing a cross) in the box against the most appropriate statement in each of the 5 dimensions. ${ }^{16,17}$ Effect of test drug was evaluated at mid and after treatment in those patients who had some (who have reported level 1or level 2) problem at baseline.

\section{c) EQ5D index value}

EQ5D index value calculation uses EQ5D descriptive system to define HRQoL values (i.e. utilities) for 245 health states. Utility (index value) was calculated at baseline, mid and after treatment, using UK based VAS value set provided by EuroQol group. Lower score of utility indicates impaired quality of life. ${ }^{16,17}$ Significant increment of utility score at mid and after treatment Vs. baseline was considered as improvement in QOL. ${ }^{16,17}$ 


\section{2) Response on physical symptoms}

17 physical symptoms related to $\mathrm{CHB}$ were evaluated i.e. fatigue, abdominal pain, muscle cramps, itching, joint pain, weakness, nausea, retrosternal burning, poor appetite, jaundice, fever, heaviness in abdomen, vomiting, loose motions, constipation, weight loss and indigestion. Patients were asked which of the following symptoms you have consistently had at least once a week for the past 4 week and severity (mild, moderate or severe) that they have most frequently been. Symptoms were analyzed in severity and graded on a four-point Likert Scale (0-3); where 0 was Nil, 1 was Mild, 2 was Moderate and 3 was Severe.

\section{a) Mean Likert scale score}

Mean likert score of each symptom at baseline was compared with mean score at $7^{\text {th }}$ day, mid and after treatment to ascertain the efficacy of test drug. Higher scores indicated severity of symptom and significant reduction of scores after treatment indicated efficacy of test drug in improving a symptom.

\section{b) Percentage of patients, relieved in a particular symptom after treatment}

Effect of treatment was also evaluated on proportion of patients who have reported symptoms on likert scale as " 1 ", " 2 " and " 3 " at baseline for each symptom, were considered "affected". Proportion of affected patients who have reported symptoms on likert scale as " 0 " after treatment, were considered "relieved". Significance in proportion of patients, relived for a particular symptoms after treatment was considered as efficacy of test drug.

\section{3) Hepatitis quality of life questionnaire $\left(\mathrm{HQLQ}^{\mathrm{TM}}\right)$ including SF-36V2 ${ }^{\text {TM }}$}

$\mathrm{HQLQ}^{\mathrm{TM}}$, version 2 is a multi-item, patient-based assessment designed to monitor the effects of chronic hepatitis and its treatment on the individual's functional status and well-being. ${ }^{18}$ The HQLQv2 consists of two parts: First, the SF-36v2 ${ }^{\circledR}$ health survey and second, generic and hepatitis (disease) specific scale. The health states associated with its lowest and highest possible scores (i.e., 0 and 100). ${ }^{18,19}$

\section{a) SF-36v2 ${ }^{\circledR}$ health survey ${ }^{19}$}

A 36-item patient self-assessment of general health that yields scores on eight health domain scales and two component summary measures. The SF36v2 has eight dimensions of health Physical Functioning (PF), Role Functioning (RF), Bodily Pain (BP), General Health (GH), Vitality (VT), Social Functioning (SF), Role Emotional (RE) and Mental Health (MH). These eight dimensions can be reduced to two summary scores: a Physical Component Summary Score (PCS) and a Mental Component Summary Score (MCS). In our study, we calculated SF36v2 scores by software provided by Optum Insight Life Science. Population norm was used to compare individual or group scores. Population norm is actually a limit of statistical normality. ${ }^{19}$

\section{b) Generic and hepatitis (disease) specific scale}

A four-scale battery of 15 supplemental items that focuses on other health domains relevant to assessing the impact of hepatitis, including general health distress, positive well-being, hepatitis-specific distress and limitations in functional status. ${ }^{19}$

For all scoring dimensions and summary scales, population norm is 50 . Low scores signal a state of poor health. High scores indicated that the patient evaluated his/ her health most favorably. ${ }^{19}$

c) Percentage of patients on PCS and MCS at, above and below the norm Results were also evaluated on percentage of patients at, above and below the norm value (50) for general population in PCS and MCS scales.
Significant increment in percentage of patients above the norm (50) at mid and after treatment Vs. patients above the norm at baseline in PCS and MCS scale was considered an improvement in physical and mental health respectively. ${ }^{18,19}$

\section{d) Risk of depression}

Some of the most important information provided by the analysis of SF-36 questionnaire data is those on the risk for depression. The questionnaire is designed to be a first-stage screen of depression in terms of risk. As per US general population norm, rate of first stage depression is $18 \%{ }^{19}$ Percentage of patients at risk of first stage depression at baseline, mid and after treatment was calculated by software provided by the Optum Insight Life Sciences.

\section{Statistical analysis}

SF36v2 scores and scores for risk of depression were calculated by software provided by Optum Insight Life Science. Normal-distributed continuous variables were calculated as mean \pm standard deviation (SD) and compared by Tukey-Kramer multiple comparisons test. Categorial variables were calculated by Fisher's exact test through GraphPad Prism, version 7.00 for windows created on March 31, 2016. Differences were considered significant when the $\mathrm{p}$ value was less than 0.05 . Test results were ranked as: ns - Non significant $p>0.05,{ }^{*} p<0.05$ significant, ${ }^{* *} p<$ 0.01 very significant, $* * * p<0.001$ extremely significant.

\section{RESULTS}

\section{Effect on EuroQol 5D-3L (EQ5D)}

\section{a) EQ5D VAS [Table 1; Figure 1]}

At baseline, mean EQ5D VAS in total patients $(n=30)$ was $20.37 \pm S D$ 14.39 which significantly increased to $62.53 \pm$ SD 12.22 at $6^{\text {th }}$ week (mid treatment). $(p<0.001)$ The VAS values furthermore significantly increased to $92.27 \pm$ SD 8.62 at $12^{\text {th }}$ week (after treatment). $(p<0.001)$.

\section{b) EQ5D descriptive [Table 2; Figure 2]}

In activities, 21 (70\%) patients had some problem at baseline which significantly reduced $(p<0.001)$ and only $2(6.66 \%)$ patients had some problem after treatment.

All the 30 patients (100\%) who have complained some problem in pain domain of EQ5D at baseline were relived (100\%) after treatment $(p<0.001)$. Among total 30 patients, 25 (83.33\%) had some amount of anxiety at baseline. After treatment only $2(6.66 \%)$ patients had reported anxiety. $(p<0.001)$.

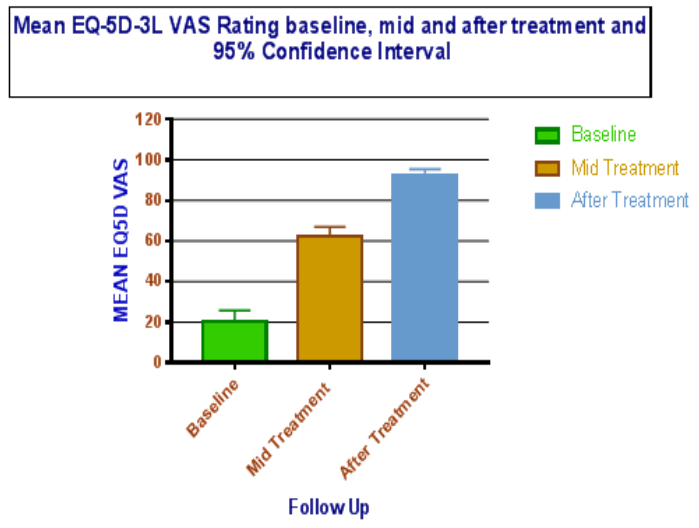

Figure 1: Effect of treatment on EQ5D-3L VAS. 


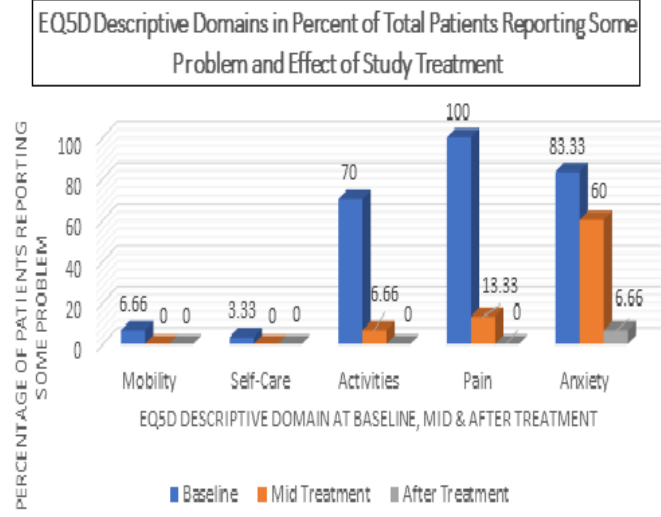

Figure 2: Effect of treatment in \% of patients reporting some problem at baseline in EQ5D descriptive domains.

\section{c) EQ5D index value [Table 3; Figure 3]}

Mean utility score of $0.58 \pm$ SD 0.03 at baseline has significantly increased to $0.83 \pm$ SD 0.02 at mid-treatment $(p<0.001)$ which further increased to $0.98 \pm$ SD 0.01 after treatment. $(p<0.001)$

\section{Effect of treatment on physical Symptoms [Table 4, 5; Figure 4, 5]}

Differences in mean likert score in each symptoms (fatigue, abdominal pain, muscle cramps, joint pain, general weakness, nausea, retrosternal burning, poor appetite, jaundice, fever, heaviness in abdomen, vomiting, loose motions, constipation, weight loss and indigestion) except itching were statistically significant from baseline Vs. after treatment and baseline Vs. mid treatment $(p<0.001)$. [Table 4] Figure 4, 5 demonstrate improvement in physical symptoms over a treatment period of 12 weeks of test drug in graphical manner. $69.23 \%$ affected patients $(n=18 / 26)$ got relived from fatigue after treatment. $90 \%(n=27 / 30)$ affected patients got relief from general weakness, $91.66 \%(n=11 / 12)$ patients relieved from jaundice and $96.29 \%$ patients relieved from joint pain after treatment. $(p<0.001) 3(10 \%)$ patients complained itching at baseline and all were relieved after treatment but $p$ value is $>0.05$ due to small number of affected patients.

\section{HQLQv2 ${ }^{\mathrm{TM}}$ (Hepatitis quality of life questionnaire ${ }^{\mathrm{TM}}$, Version 2)}

a) Effect of treatment on HQLQV2 ${ }^{\mathrm{TM}}$ part 1: SF-36V $2^{\circledR}$ health survey [Table 6; Figure 6]

Mean PCS score at baseline was $41.21 \pm$ SD 6.33 which was upgraded to $52.58 \pm \mathrm{SD} 4.44$ at mid- treatment significantly $(p<0.001)$. The mean score furthermore significantly upgraded to $57.44 \pm \mathrm{SD} 2.16$ after treatment. $(p<0.001)$

MCS (Mental Component summary): Mean MCS score at baseline was $32.41 \pm$ SD 10.27 which upgraded to $51.8 \pm$ SD 5 at mid-treatment significantly $(p<0.001)$. The mean score furthermore significantly upgraded to $58.6 \pm$ SD 2.24 after treatment. $(p<0.001)$

The mean score of physical functioning $(\mathrm{PF})$, role functioning $(\mathrm{RF})$, bodily pain (BP), general health $(\mathrm{GH})$, vitality $(\mathrm{VT})$, social functioning $(\mathrm{SF})$, role emotional $(\mathrm{RE})$ and mental health $(\mathrm{MH})$ at baseline were 43.12 , $35.82,37.51,34.98,41.51,31.77,30.17$ and 35.87 respectively which were below the norm (50) for general population. At mid-treatment, mean score of PF, RF, BP, GH, VT, SF, RE and MH were upgraded to 54.22, $49.67,54.77,47.24,60.32,50.99,48.51$ and 52.26 which furthermore upgraded to $56.46,56.94,61.73,54.9,65.27,56.17,56.17$ and 58.54 respectively after treatment.

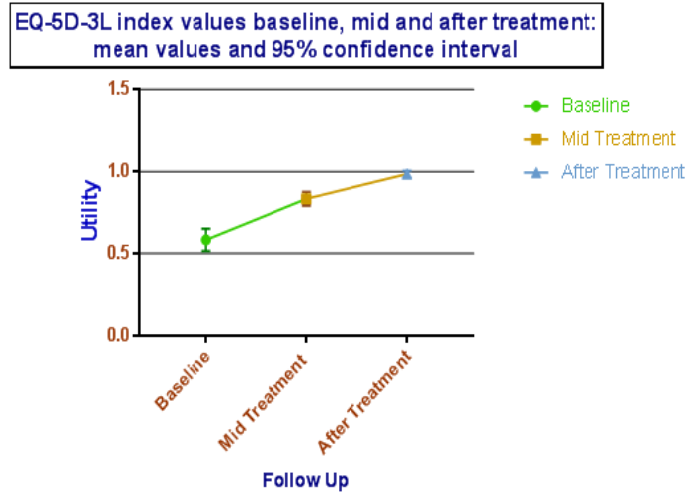

Figure 3: Effect of treatment on EQ5D index values.

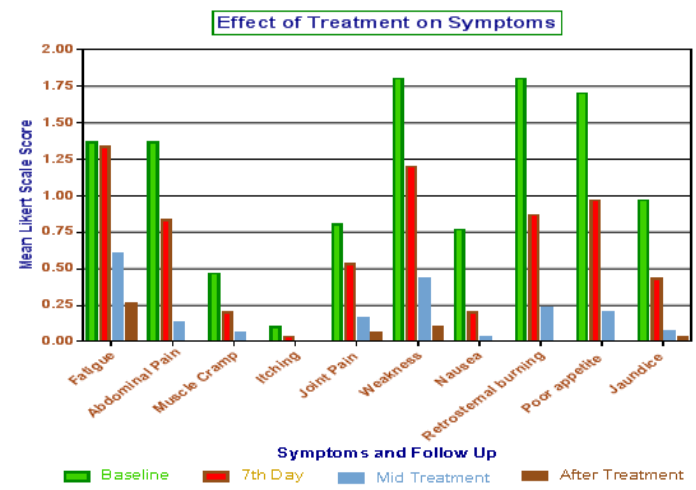

Figure 4: Effect of treatment on symptoms.

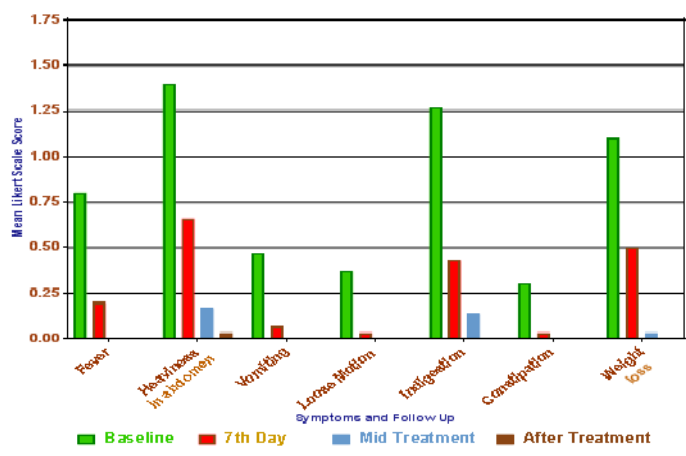

Figure 5: Effect of treatment on symptoms.

Table 1: EQ5D VAS values and effect of treatment.

\begin{tabular}{ccccc} 
EQ5D VAS & Baseline & $\begin{array}{c}\text { Mid } \\
\text { Treatment }\end{array}$ & $\begin{array}{c}\text { After } \\
\text { Treatment }\end{array}$ & p value \\
\hline Mean & 20.37 & 62.53 & 92.27 & \\
SD & 14.39 & 12.22 & 8.626 & ${ }^{*} p<0.001$ \\
Median & 15.5 & 60 & 95 & ${ }^{*} p<0.001$ \\
$25^{\text {th }}$ & 10 & 53.75 & 90 & \\
$75^{\text {th }}$ & 30 & 70 & 99.25 & \\
$\mathrm{~N}$ & 30 & 30 & 30 & \\
\hline
\end{tabular}

*Baseline Vs. Mid treatment; \#Baseline Vs. After treatment. 
Table 2: EQ5D descriptive domains at baseline, mid and after treatment.

\begin{tabular}{ccccc}
\hline \multirow{2}{*}{$\begin{array}{c}\text { EQ5D-3L } \\
\text { descriptive } \\
\text { domains }\end{array}$} & Levels & \multicolumn{3}{c}{ Total } \\
\cline { 3 - 5 } & & B $\mathbf{n}=30)$ Frequency (Percentage) \\
\hline \multirow{2}{*}{ Mobility } & No problem & $28(93.33)$ & $30(100)$ & $30(100)$ \\
& Some problem & $2(6.66)$ & $0(0)$ & $0(0) \dagger$ \\
& No problem & $29(96.66)$ & $30(100)$ & $30(100)$ \\
Self-Care & Some problem & $1(3.33)$ & $0(0)$ & $0(0) \dagger$ \\
& No problem & $9(30)$ & $28(93.33)$ & $30(100)$ \\
Activities & Some problem & $21(70)$ & $2(6.66)$ & $0(0)^{*}$ \\
& No problem & $0(0)$ & $26(86.66)$ & $30(100)$ \\
Pain & Some problem & $30(100)$ & $4(13.33)$ & $0(0)^{\S}$ \\
& No problem & $5(16.66)$ & $12(40)$ & $28(93.33)$ \\
Anxiety & Some problem & $25(83.33)$ & $18(60)$ & $2(6.66)^{\gamma}$ \\
\hline
\end{tabular}

Baseline Vs. After treatment $\uparrow p>0.05 ; \# p<0.001 ; \$ p<0.001 ; \gamma p<0.001$.
Table 3: Effect of treatment on EQ5D Index Values.

\begin{tabular}{rrrrr}
$\begin{array}{r}\text { EQ5D Index } \\
\text { Value }\end{array}$ & Baseline & $\begin{array}{r}\text { Mid } \\
\text { Treatment }\end{array}$ & $\begin{array}{r}\text { After } \\
\text { Treatment }\end{array}$ & p Value \\
\hline Mean & 0.583 & 0.834 & 0.985 & $* p<0.001$ \\
$\rightarrow$ Std. & 0.033 & 0.020 & 0.0100 & \\
Error & & & & \\
Median & 0.667 & 0.782 & 1 & \\
$\rightarrow 25^{\text {th }}$ & 0.3993 & 0.7768 & 1 & \\
Percentile & & & & \\
$\rightarrow 75^{\text {th }}$ & 0.698 & 1 & 1 & $\$ p<0.001$ \\
Percentile & & 30 & 30 & \\
$\mathrm{~N}$ & 30 & 30 & & \\
\hline
\end{tabular}

*Baseline Vs. Mid Treatment; \# Baseline Vs. After Treatment; $₫$ Mid Vs. After Treatment.

Table 4: Effect of treatment on physical symptoms in total patients $(n=30)$.

\begin{tabular}{|c|c|c|c|c|c|}
\hline \multirow{2}{*}{ Physical symptoms } & \multicolumn{4}{|c|}{ Mean Value \pm Standard Deviation } & \multirow{2}{*}{$p$ Value } \\
\hline & Baseline & $7^{\text {th }}$ Day & Mid Treatment & After Treatment & \\
\hline Fatigue & $1.367 \pm 0.8087$ & $1.133 \pm 0.6288$ & $0.6 \pm 0.4983$ & $0.2667 \pm 0.4498$ & $\dagger p>0.05 . \# p<0.0001 .{ }^{\gamma} p<0.0001$ \\
\hline Abdominal pain & $1.367 \pm 0.6687$ & $0.8333 \pm 0.5921$ & $0.1333 \pm 0.3457$ & $0 \pm 0$ & $\dagger p<0.001 . \# p<0.001 .{ }^{\gamma} p<0.001$ \\
\hline Muscle cramp & $0.466 \pm 0.6814$ & $0.2 \pm 0.4068$ & $0.0666 \pm 0.2537$ & $0 \pm 0$ & $\dagger p<0.001 . \# p<0.001 .{ }^{\gamma} p<0.001$ \\
\hline Itching & $0.1 \pm 0.3051$ & $0.0333 \pm 0.1826$ & $0 \pm 0$ & $0 \pm 0$ & $\dagger p>0.05 . \# p>0.05 .{ }^{\gamma} p>0.05$ \\
\hline Joint pain & $0.8 \pm 0.7144$ & $0.5333 \pm 0.5074$ & $0.1667 \pm 0.379$ & $0.0666 \pm 0.2537$ & $\dagger p>0.05 . \# p<0.001 .{ }^{\gamma} p<0.001$ \\
\hline Weakness & $1.8 \pm 0.8052$ & $1.2 \pm 0.5509$ & $0.4333 \pm 0.5683$ & $0.1 \pm 0.3051$ & $\dagger p=0.001 . \# p<0.001 .{ }^{\gamma} p<0.001$ \\
\hline Nausea & $0.766 \pm 0.7279$ & $0.2 \pm 0.4068$ & $0.0333 \pm 0.1826$ & $0 \pm 0$ & $\dagger p<0.001 . \# p<0.001 .{ }^{\gamma} p<0.001$ \\
\hline Retrosternal burning & $1.8 \pm 0.7611$ & $0.8667 \pm 0.8193$ & $0.2333 \pm 0.4302$ & $0 \pm 0$ & $\dagger p<0.001 . \# p<0.001 .{ }^{\gamma} p<0.001$ \\
\hline Poor appetite & $1.7 \pm 1.119$ & $0.9667 \pm 0.8899$ & $0.2 \pm 0.4068$ & $0 \pm 0$ & $\dagger p<0.01 . \# p<0.001 .{ }^{\gamma} p<0.001$ \\
\hline Jaundice & $0.967 \pm 0.7649$ & $0.4333 \pm 0.5683$ & $0.0666 \pm 0.2537$ & $0.0333 \pm 0.1826$ & $\dagger p<0.001 . \# p<0.001 .{ }^{\gamma} p<0.001$ \\
\hline Fever & $0.8 \pm 0.5509$ & $0.2 \pm 0.4068$ & $0 \pm 0$ & $0 \pm 0$ & $\dagger p<0.001 . \# p<0.001 .{ }^{\gamma} p<0.001$ \\
\hline Heaviness in abdomen & $1.4 \pm 0.724$ & $0.6667 \pm 0.5467$ & $0.1667 \pm 0.379$ & $0.0333 \pm 0.1826$ & $\dagger p<0.001 . \# p<0.001 .{ }^{\gamma} p<0.001$ \\
\hline Vomiting & $0.4667 \pm 0.571$ & $0.0666 \pm 0.2537$ & $0 \pm 0$ & $0 \pm 0$ & $\dagger p<0.001 . \# p<0.001 .{ }^{\gamma} p<0.001$ \\
\hline Loose motions & $0.366 \pm 0.4901$ & $0.0333 \pm 0.1826$ & $0 \pm 0$ & $0 \pm 0$ & $\dagger p<0.001 . \# p<0.001 .{ }^{\gamma} p<0.001$ \\
\hline Indigestion & $1.267 \pm 0.6397$ & $0.4333 \pm 0.504$ & $0.1333 \pm 0.3457$ & $0 \pm 0$ & $\dagger p<0.001 . \# p<0.001 .{ }^{\gamma} p<0.001$ \\
\hline Constipation & $0.3 \pm 0.596$ & $0.03333 \pm 0.1826$ & $0 \pm 0$ & $0 \pm 0$ & $\dagger p<0.01 . \# p<0.01 .{ }^{\gamma} p<0.01$ \\
\hline Weight loss & $1.1 \pm 0.8847$ & $0.5 \pm 0.5724$ & $0.0333 \pm 0.1826$ & $0 \pm 0$ & $\dagger p<0.001 . \# p<0.001 .{ }^{\gamma} p<0.001$ \\
\hline
\end{tabular}

$\dagger$ Baseline Vs. $7^{\text {th }}$ Day; \#Baseline Vs. Mid treatment; $\gamma$ Baseline Vs. After treatment.

b) Effect of treatment on HQLQv2TM part 2: Generic and hepatitis (disease) specific scale [Table 7; Figure 7]

The mean score of four scales i.e. generic health distress, positive well-being, hepatitis specific limitation and hepatitis specific distress at baseline were $39.66 \pm$ SD $21.04,35.16 \pm$ SD 20.28, 45.99 \pm SD 23.83 and $36.33 \pm$ SD 25.01 which were significantly upgraded to $80.5 \pm$ SD $11.54,68.83 \pm S D$ $10.23,85.11 \pm$ SD 12.35 and $82 \pm$ SD 11.93 at mid-treatment $(p<0.001)$ which were further upgraded to $95 \pm$ SD $3.806,83.66 \pm$ SD 7.30, 97.33 \pm SD 4.14 and $95 \pm$ SD 4.15 significantly after treatment. $(p<0.001)$ c) Effect of treatment on percentage of patients on physical component summary (PCS) and mental component summary (MCS) score at, above and below the norm [Figure 8]

$67 \%$ and $87 \%$ of patients were below the norm at baseline in PCS and MCS scoring respectively. At mid-treatment only $3 \%$ patients in PCS and 7\% patients in MCS were below the norm. After treatment, no patient $(0 \%)$ was below the norm in both summary scores. 


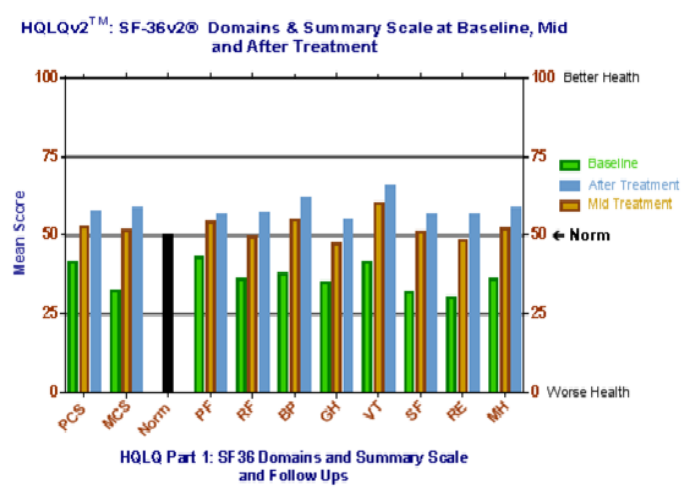

Figure 6: HQLQ: $\mathrm{SF}-36 \mathrm{v} 2^{\circledR}$ scale and effect of treatment on scores for total lot.

PCS (Physical Component Summary), MCS (Mental Component Summary), PF (Physical Functioning), SF (Social Functioning), BP (Bodily Pain), GH (General Health), VT (Vitality), SF (Social Functioning), RE (Role Emotional), MH (Mental Health).

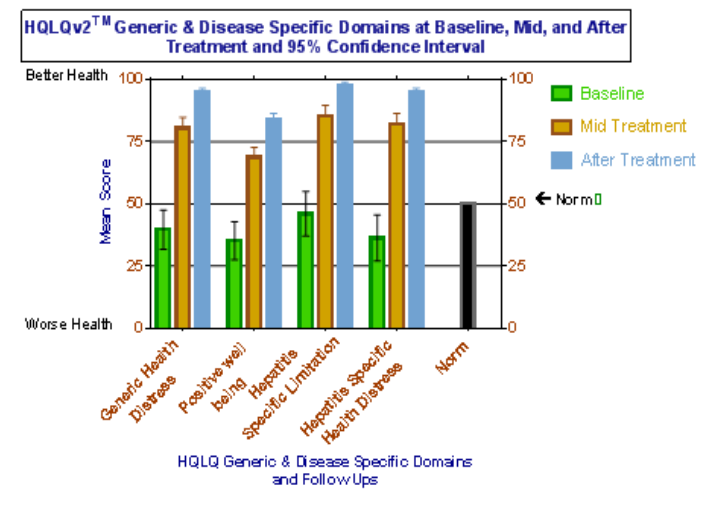

Figure 7: HQLQ generic \& disease specific scale mean score and $95 \%$ confidence interval and effect of treatment.

\section{d) Effect of treatment in risk of depression [Figure 9]}

In our study, $83 \%$ patients at baseline were at risk of first stage depression. $3 \%$ of the patients at mid-treatment and no $(0 \%)$ patient after treatment have shown risk of first stage depression

\section{DISCUSSION}

Symptomatic $\mathrm{CHB}$ results in impairment in the quality of life of the patients. ${ }^{16}$ In our study, we have observed that patients with more chronicity of disease had more deranged quality of life. Negativity about life and health was also observed in our study patients.

The overall utility score for CHB patients in our study was lower than normal population as shown in baseline EQ5D index values of our study patients. [Table 3] Other studies have also reported low utility score in $\mathrm{CHB}$ with further decrement in scores as disease progresses to an advanced stage. The more severe the disease status, lower the utility score has been observed. ${ }^{16,17}$

The significant increase in values of VAS during and after course of treatment $(p<0.001)$ showed improvement in quality of life Vs. baseline. (Figure 3) However mean increase was higher between baseline and mid-treatment than between mid-treatment and after treatment. The fact is most patients have experienced improvement in their long-standing physical symptoms and work abilities within 4 weeks of study from baseline. In India, negativity easily generates especially with chronic diseases like Hepatitis B in low income class. Low economy and restricted healthcare access are another important issues which put patients in risk
Table 5: Effect of treatment on number of patients with physical symptoms.

\begin{tabular}{|c|c|c|c|c|}
\hline \multirow{2}{*}{ Symptom } & \multirow{2}{*}{$\begin{array}{l}\text { †Affected } \\
\text { (Number of } \\
\text { Patients) } \\
\text { Baseline }\end{array}$} & \multicolumn{2}{|c|}{$\begin{array}{c}\text { \#Relieved } \\
\text { After Treatment }\end{array}$} & \multirow[t]{2}{*}{$p$ Value } \\
\hline & & Number & Percentage & \\
\hline Fatigue & 26 & 18 & 69.23 & $p<0.001$ \\
\hline Abdominal Pain & 27 & 27 & 100 & $p<0.001$ \\
\hline Muscle cramp & 11 & 11 & 100 & $p<0.001$ \\
\hline Itching & 3 & 3 & 100 & $p>0.05$ \\
\hline Joint pain & 18 & 16 & 88.88 & $p<0.001$ \\
\hline Weakness & 30 & 27 & 90 & $p<0.001$ \\
\hline Nausea & 18 & 18 & 100 & $p<0.001$ \\
\hline $\begin{array}{l}\text { Retrosternal } \\
\text { burning }\end{array}$ & 29 & 29 & 100 & $p<0.001$ \\
\hline Poor appetite & 25 & 25 & 100 & $p<0.001$ \\
\hline Jaundice & 12 & 11 & 91.66 & $p<0.001$ \\
\hline Fever & 22 & 22 & 100 & $p<0.001$ \\
\hline $\begin{array}{l}\text { Heaviness in } \\
\text { abdomen }\end{array}$ & 27 & 26 & 96.29 & $p<0.001$ \\
\hline Vomiting & 13 & 13 & 100 & $p<0.001$ \\
\hline Loose motions & 11 & 11 & 100 & $p<0.001$ \\
\hline Indigestion & 27 & 27 & 100 & $p<0.001$ \\
\hline Constipation & 7 & 7 & 100 & $p<0.001$ \\
\hline Weight loss & 22 & 22 & 100 & $p<0.001$ \\
\hline \multicolumn{3}{|c|}{$\begin{array}{l}\text { Percentage of patients achieved complete } \\
\text { symptomatic relief at } 12^{\text {th }} \text { week (after treatment) }\end{array}$} & \multicolumn{2}{|c|}{$70 \%$} \\
\hline
\end{tabular}

$\dagger$ Patients who have reported symptoms on Likert Scale as"1", "2" \& "3" at Baseline. \#Affected patients who have reported symptoms on Likert Scale as "0" after treatment.

of depression. ${ }^{20,21}$ That's why our patients interpreted their health highly improved at $6^{\text {th }}$ week and extremely different from health at before treatment.

In different EQ5D descriptive domains, we have evaluated effect of test drug in those who had some (who have reported level 1or level 2) problem. Table 2 demonstrates that $\mathrm{CHB}$ in the absence of cirrhosis or advanced diseases like HCC rarely causes problem in mobility and selfcare. Only $2(6.66 \%)$ patients at baseline had some problem in mobility while only $1(3.33 \%)$ patient had some problem in self-care. These patients were improved by test drug and no patient reported problem in mobility and self-care after treatment.

Figure 2 shows that high proportion of patients (83.33\%) reported anxiety in EQ5D descriptive domain in our study especially observed with those female who were unmarried and had stigma of being HBsAg positive in marriage proposals. Similarly those patients who were rejected in medico-legal testing for international jobs were highly anxious about their health because of low economy and family burdens. Two anxious patient were chefs which were tested positive during hotel staff medicaltesting and were advised to get treated as soon as possible.

The plausible reason of relief in anxiety in our study patients could be due to improvement in physical symptoms significantly, thus the Quality of Life (QOL). [Table 4; Figure 4,5] Relief in physical symptoms has reduced the worry and negativity about health and life. Holistic environment of MUH has also added this effect. 


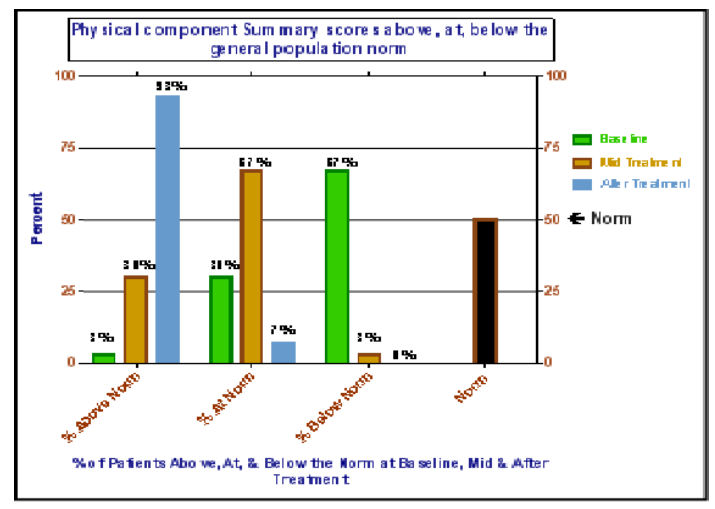

Figure 8: Effect of treatment on \% of patients above, at, below the norm in PCS and MCS.

Table 6: HQLQ: SF-36v2 ${ }^{\circledR}$ and effect of treatment aggregate (mean) score of total patients.

\begin{tabular}{|c|c|c|c|}
\hline Domains & Baseline & $\begin{array}{l}\text { Mid } \\
\text { Treatment }\end{array}$ & $\begin{array}{l}\text { After } \\
\text { Treatment }\end{array}$ \\
\hline $\begin{array}{l}\text { Physical Component Summary } \\
\text { (PCS) }\end{array}$ & $\begin{array}{l}41.21(\mathrm{SD} \\
6.333)\end{array}$ & $\begin{array}{c}52.58(\mathrm{SD} \\
4.442) \dagger\end{array}$ & $\begin{array}{l}57.44(\mathrm{SD} \\
2.168) \#\end{array}$ \\
\hline $\begin{array}{l}\text { Mental Component Summary } \\
\text { (MCS) }\end{array}$ & $\begin{array}{l}32.41(\mathrm{SD} \\
10.27)\end{array}$ & $51.8(\mathrm{SD} 5) \dagger$ & $\begin{array}{c}58.6(\mathrm{SD} \\
2.238) \#\end{array}$ \\
\hline Physical Functioning (PF) & 43.12 & 54.22 & 56.46 \\
\hline Role Functioning (RF) & 35.82 & 49.67 & 56.94 \\
\hline Bodily Pain (BP) & 37.51 & 54.77 & 61.73 \\
\hline General Health (GH) & 34.98 & 47.24 & 54.9 \\
\hline Vitality (VT) & 41.51 & 60.32 & 65.27 \\
\hline Social Functioning (SF) & 31.77 & 50.99 & 56.17 \\
\hline Role Emotional (RE) & 30.17 & 48.51 & 56.17 \\
\hline Mental Health (MH) & 35.87 & 52.26 & 58.54 \\
\hline
\end{tabular}

$\dagger$ Baseline Vs. Mid treatment $p<0.001$; \#Baseline Vs. After treatment $<0.001$.

Table 7: HQLQv2 ${ }^{\mathrm{TM}}$ Hepatitis specific scale and effect of treatment Mean (SD).

\begin{tabular}{ccccc}
\hline & Baseline & $\begin{array}{c}\text { Mid } \\
\text { Treatment }\end{array}$ & $\begin{array}{c}\text { After } \\
\text { Treatment }\end{array}$ & $p$ Value \\
\hline $\begin{array}{c}\text { Generic health } \\
\text { distress }\end{array}$ & $\begin{array}{c}\text { (21.04) } \\
\text { (2.66 }\end{array}$ & $\begin{array}{c}80.5 \\
(11.54)\end{array}$ & $95(3.806)$ & $\dagger p<0.001$. \\
Positive well & 35.16 & 68.83 & 83.66 & $\dagger p<0.001$. \\
being & $(20.28)$ & $(10.23)$ & $(7.303)$ & $\# p<0.001$. \\
& & & & \\
Hepatitis specific & 45.99 & 85.11 & 97.33 & $\dagger p<0.001$. \\
limitation & $(23.83)$ & $(12.35)$ & $(4.145)$ & $\# p<0.001$. \\
$\begin{array}{c}\text { Hepatitis specific } \\
\text { distress }\end{array}$ & 36.33 & $82(11.93)$ & $95(4.154)$ & $\dagger p<0.001$. \\
& $(25.01)$ & & & $\# p<0.001$. \\
\hline
\end{tabular}

$\dagger$ Baseline Vs. Mid treatment; \#Baseline Vs. After treatment.

Lower score of mean utility in study patients, $0.58 \pm$ SD 0.03 at baseline showed impaired quality of life. [Table 3] Levy et al. reported through a multinational study that utility can be observed as low as 0.30 in cirrhosis and HCC. In CHB, generally it is 0.60 and always lower than general population. ${ }^{14}$ Woo et al. have studied cirrhotic and non-cirrhotic CHB patients and evaluated the efficacy of antiviral treatment in their utili- ties. They observed that with respect to the effect of antiviral therapy on quality of life, there was no statistically significant difference in adjusted utility scores between patients on and off treatment, regardless of disease severity $(p>0.05){ }^{6}$ This infer that daily oral antiviral treatment is not associated with lower or higher scores in QOL instruments while administration of test drug showed highly significant difference in utility score between baseline and after treatment $(p<0.001)$ [Table 3; Figure 3], thus the test drug is eligible to improve QOL.

Inefficacious effect of antivirals on utility score presumably could be due to its inability in reducing physical symptoms, associated adverse effects such as gastro-intestinal disturbances (nausea, vomiting, diarrhea, dizziness etc.), nephrotoxicity, myopathy, thrombocytopenia and severe ALT flares and long costly treatment including resistance. ${ }^{3-5}$

Table 4 shows effect of treatment on proportion of patients who have reported symptoms on Likert Scale as " 1 ", " 2 " and " 3 " at baseline for each symptom, were considered "affected". Proportion of affected patients who have reported symptoms on Likert Scale as "0" after treatment, were considered "relieved".

For each symptom except itching, proportion of patients presented "affected" at baseline was significantly different from those remained after treatment $(p<0.001)$. Relief of all the "affected" patients $(100 \%)$ after treatment was achieved in symptoms such as abdominal pain, muscle cramps, weakness, nausea, retrosternal burning, poor appetite, fever, vomiting, loose motions, constipation, weight loss and indigestion. $(p<0.001)$ [Table 5]

These findings imply that the test drug can improve physical symptoms of CHB. Apart from other reasons such as no adverse effects, relief from physical symptoms was the sole cause of adherence and compliance of the patients in our study.

Both PCS and MCS of SF-36v2 of HQLQv2 ${ }^{\mathrm{mm}}$ are the measure of physical and mental health (PH and $\mathrm{MH})$. Table 6 demonstrates that the mean baseline score of PCS and MCS were below the norm (50) for general population which revealed deranged $\mathrm{PH}$ and $\mathrm{MH}$ in our study patients. But at mid and after treatment, mean PCS and MCS scores were upgraded and were more than norm $(50)$ for general population. $(p<0.001)$ [Table 6; Figure 6]

Figure 8 demonstrate that the $67 \%$ and $87 \%$ patients in PCS and MCS respectively, were below the norm at baseline. After treatment, no patient was below the norm in both summary scales. These findings showed that our study patients had poor health status at baseline and test drug has improved physical and mental health significantly after treatment, thus QoL.

The mean score of eight domains of SF-36v2 at baseline were below the norm (50) for general population. Highest score of 65.27 was recorded in VT while lowest score of 30.17 was reported in role emotional (RE) but mean value of total patients was without reaching the normal levels in the general population. The low scores on RE scale show the extent to which emotional problems of a person limit him/her in usual activities, e.g. childcare, professional activities, etc. ${ }^{19}$ Teodor et al. reported lower score in RE and highest score in VT in their study in chronic Hepatitis C, similar to our study. ${ }^{22}$ [Table 6]

The mean score of four scales i.e. generic health distress, positive wellbeing, hepatitis specific limitation and hepatitis specific distress of HQLQv2 ${ }^{\mathrm{TM}}$ were below the norm thereafter significantly upgraded $(p<0.001)$ and were more than norm (50) after treatment. [Table 7] These observations shows that the test drug is effective in managing hepatitis related deranged health, thus QOL [Figure 7].

In our study, $83 \%$ patients at baseline were at risk of first stage depression and after treatment no (0\%) patient has shown risk. $18 \%$ is the norm for the general population. The possible reason could be due to highly significant relief in physical symptoms in our patients $(p<0.0001)$. [Figure 4,5 ,] This finding also upholds the improvements observed in various 
health domains of SF-36v2. The association of psychological and physical problems in patients suffering from Hepatitis B is demonstrated by the significant correlation between Role Emotional (RE), mentioned above and Role Physical (RP) which measures the same limitations as RE but due to physical health (Pearson Correlation $r=0.653, p<0.001$ ). ${ }^{22}$ The improvement in physical and mental health observed in our study can also be attributed to the effect of test drug, Saussurea lappa $a^{23-29}$ and Artemisia absinthium ${ }^{25,29-31}$ which have been used by Unani scholars as brain tonics since ages. Various studies have also exhibited their efficacy as brain and general tonic. ${ }^{32}$ Ahmoudi et al. reported antidepressant activity of Artemisia absinthium in an animal study. ${ }^{33}$ Ansari et al. have reported antiviral and hepatocurative activity of these drugs in clinical trial which could be the plausible reason of improvements observed in various health instruments. ${ }^{10,11}$ Limitation of the study includes small sample size and short duration of protocol therapy due to financial constraints. There was no placebo or active treatment for comparison and cirrhotic patients were exclusionary criteria's (as per suggestions of ethical committee) in our pre-, mid- and post-treatment study. Hence, controlled clinical studies with large sample size including cirrhotic patient should be done.

\section{CONCLUSION}

Improvement in quality of life (EQ5D, HQLQ and physical symptoms) was observed which uphold the objective that the test drug can improve interrelated deranged physical and mental health associated with $\mathrm{CHB}$. Almost all the patients had improvement in their physical symptoms, one of a reason for compliance of the patients in our study.

\section{ACKNOWLEDGEMENT}

Authors appreciate the cooperation of all the study patients in the study. We are also thankful of Optum Insight Life Science and EuroQol Group for providing us their questionnaires and calculating software for the study.

\section{CONFLICT OF INTEREST}

The authors declare no conflict of interest.

\section{ABBREVIATIONS}

CHB: Chronic Hepatitis B; HBV: Hepatitis B virus; Qol: Quality of life; EQ5D: EuroQol 5D-3L; HQLQ ${ }^{\mathrm{m}}$ : Hepatitis quality of life questionnaire; VAS: Visual analogue scale; PH: Physical health; MH: Mental health; HCC: Hepatocellular carcinoma; PCS: Physical component summary; MCS: Mental component summary; RE: Role emotional; GH: General Health; PF: Physical Functioning; RF: Role Functioning; BP: Bodily Pain; VT: Vitality; SF: Social Functioning.

\section{REFERENCES}

1. World health organisation (WHO). Hepatitis B. 2018 [Cited 2018 August 30] Available from: http://www.who.int/news-room/fact-sheets/detail/hepatitis-b.

2. World health organisation (WHO). Guidelines for the prevention, care and treatment of persons with chronic hepatitis b infection. 2015;19. [Cited 2018 August 30l. Available from: http://apps.who.int/iris/bitstream/handle/10665/154590/9789241549059_eng.pdf;jsessionid=3F1D9E7B614BD0CD 8C3D4058A3FF66B4? sequence=1.

3. Warner N, Stephen L. Replication of Hepatitis B Virus. In: BoyerTD, Manns MP Sanyal AJ. Zakim and Boyers Hepatology. $6^{\text {th }}$ ed. Cananda: Elsevier. 2012;86-94.

4. Han KH, Kim DY. Chronic HBV infection with persistently normal ALT b. not to treat. Hepatol Int. 2008;2(2):185-9

5. Terrault NA, Lok ASF, McMahon BJ, et al. Update on prevention, diagnosis and treatment of chronic hepatitis B: AASLD 2018 hepatitis B guidance. Hepatology. 2018;67(4):1560-99

6. Woo G, Tomlinson G, Yim C, Lilly L, Therapondos G, Wong D. Health state utilities and quality of life in patients with Hepatitis B. An J Gastroenterol. 2012;26(7):445-52.

7. Ansari S, Khan QA, Anjum R, Siddiqui A, Sultana K. Fundamentals of Unani system of medicine-a review. European Journal of Biomedical and Pharmaceutical Sciences. 2017;4(9):219-23

8. Ansari S, Siddiqui MA, Zaman F. Therapeutic principles of liver diseases in Unani medicine. J Res Educ Indian Med. 2015;21:101-5.

9. Ibne S. Al-Qanoon Fit-tibb [Kantoori GH Trans]. New Delhi: Aijaz Publishing House. 2010;268-439. Part 5.

10. Ansari S, Siddiqui MA, Maaz M. Hepatocurative Effect of Saussurea lappa, CB Clarke and Artemisia absinthium, Linn in Chronic Hepatitis B. J Young Pharm. 2018;10(3):354-7.

11. Ansari S, Siddiqui MA, Malhotra S, Maaz M. Antiviral efficacy of qust (Saussurea lappa) and afsanteen (Artemisia absinthium) for chronic Hepatitis B: A prospective single-arm pilot clinical trial. Phcog Res. 2018;10(3):282-90.

12. Chen HC, Chou CK, Lee SD, Wang JC, Yeh SF. Active compounds from Saussurea lappa Clarks thatsuppress hepatitis B virus surface antigen gene expression in human hepatoma cells. Antiviral Res. 1995;27(1-2):99-109. [PMID: 7486962]

13. National Clinical Guideline Centre (NICE). Hepatitis B (chronic): Diagnosis and management of chronic hepatitis $B$ in children, young people and adult. 2013:13-5. [Cited 2014 Jan 7]. Available from: http://www.nice.org.uk/guidance/ cg165/resources/cg165-hepatitis-b-chronic-full-guideline3

14. Levy AR, Kowdley KV, lloeje $U$, et al. The impact of chronic hepatitis B on quality of life: A multinational study of utilities from infected and uninfected persons. Value Health. 2008;11(3):527-38

15. Woo G. Evolving paradigms in the treatment of hepatitis B [Phd Thesis] Australia: University of Toronto. 2010;63,85,93,99. [Cited 2015 Sep 28]. Available from: https://tspace.library.utoronto.ca/bitstream/1807/32961/6/Noo_ Gloria_W_201006_PhD_thesis.pdf.

16. The Euro Qol Group. Euro Qol-a new facility for the measurement of healthrelated quality of life. Health Policy. 1990;16(3):199-208.

17. Brooks R. Euro Qol: The current state of play. Health Policy. 1996;37(1):53-72.

18. Bayliss MS, Maruish ME. Hepatitis Quality of Life Questionnaire, Version 2 (HQLQv2): Administration and scoring supplement. Lincoln, RI: Quality Metric Incorporated. 2004

19. Ware JE, Kosisnski M. SF-36® Physical and Mental Summary Scales: A Manual for Users of Version 1. $2^{\text {nd }}$ ed. Lincoln RI: Quality Metric Incorporated. 2001.

20. Siddiqui MA, Ansari S, Khan QA. Socio-demographic profile of health camp on viral hepatitis B and C at Maswasi, Rampur. Middle East Journal of Rehabilitation of Health. 2017;4(2):e44359.

21. Kumar M, Sarin SK. Viral hepatitis eradication in India by $2080-$ gaps, challenges and targets. Indian J Med Res. 2014;140(1):1-4. [PubMed: 25222771].

22. Teodor D, Juganariu G, Miftode E. Use of sf-36 questionnaire in evaluating the quality of life of hepatitis C patients on antiviral therapy - pilot study. Revista De Cercetare Si Interventie Sociala. 2014;44:253-6.

23. Ibne S. (Avicenna). Al-Qanoon Fit-Tibb [Kantoori GH, Trans]. New Delhi: Aijaz Publishing. 2010;3: 854-854-859-862, 869-78. part 1.

24. NMCD (Natural Medicine Comprehensive Database): Costus [Monograph online]. 2015. [Cited 2015 May 27]. Available from: http://naturaldatabase.therapeuticresearch.com/nd/Search.aspx?pt=100\&id=855\&AspxAutoDetectCookie Support=1.

25. Nadkarni KM. Indian Materia Medica. $3^{\text {rd }}$ ed. India: Popular Prakashan Pvt. Ltd. 2013;141-2.

26. The Unani Pharmacopea of India: Qust. New Delhi: Central council for research in Unani medicine. Part 1st. 2007;1:74-6.

27. Kirtikar KR, Basu BD. Indian Medicinal Plants. $2^{\text {nd }}$ ed. India: International book distributors. 1988;2:1420-3.

28. Kabiruddin. Makhzan-ul-Mufradat Maaroof Khwas-ul-Adviyah. New Delhi: Aijaz Publishing House. 80

29. Razi Z. Kitabul A. $3^{\text {rd }}$ ed. New Delhi: Central council for research in Unani Medicine. 2000;43

30. The Wealth of India. Artemisia Linn. India: Publication and Information Directorate, CSIR. 1985;1:434-5

31. The Unani Pharmacopea of India: Afsateen. New Delhi: Central council for research in Unani Medicine Part 1. 2007;2:3-4

32. Wake G, Court J, Pickering A, Lewis R, Wilkins R, Perry E. CNS acetylcholine receptor activity in European medicinal plants traditionally used to improve failing memory. Journal of Ethnopharmacology. 2000;69(2):105-14.

33. Ahmoudi M, Ebrahimzadeh MA, Ansaroudi F, Nabavi SF, Nabavi SM. Antidepressant and antioxidant activities of Artemisia absinthium L. at flowering stage. African Journal of Biotechnology. 2009;8(24):7170-5. 